picture of hyperthyroidism would usually be considered a reasonably strong point against the diagnosis, especially in young patients, and the finding of a low thyroid uptake of radioactive iodine would be accepted by most people as evidence justifying exclusion of the disease. In such circumstances the physician should think of unusual causes of hyperthyroidism-thyrotoxicosis factitia, the effect of exogenous iodide ingestion, or, very rarely, struma ovarii, hydatidiform mole, or metastatic functioning follicular carcinoma of the thyroid.

Recent descriptions of this form of thyroiditis deserve wider recognition, for these patients do not require the usual definitive forms of treatment for this disease-the hyperthyroidism seems to be transient. A short course of propranolol may be enough to tide the patient over the transient hyperthyroid state, and little more needs to be done apart from careful follow-up to detect possible hypothyroidism.

${ }^{1}$ Greene, J N, American fournal of Medicine, 1971, 51, 97.

2 Dorfman, S G, et al, Annals of Internal Medicine, 1977, 86, 24

${ }^{3}$ Woolf, P D, and Daly, R, American fournal of Medicine, 1976, 60, 73.

4 Papapetrou, P D, and Jackson, I M D, Lancet, 1975, 1, 361.

${ }^{5}$ Jackson, I M D, New England fournal of Medicine, 1975, 293, 661.

\section{Painful diabetic neuropathy}

Pain is an uncommon but disabling feature of diabetic neuropathy, unremitting, with characteristic cutaneous hypersensitivity leading to acute discomfort on contact with clothing. Constant burning sensations, paraesthesiae, or shooting pains may also occur, and, like the other symptoms, these are especially severe at night, possibly causing insomnia and depression. ${ }^{1}$ Severe loss of weight is the rule, which together with the protracted pain may lead to extensive investigations, often for malignant disease, ${ }^{1-3}$ before the true diagnosis is made. Ellenberg ${ }^{1}$ used the description of neuropathic cachexia for some of these patients. The syndrome is much commoner in men than in women and occurs chiefly in patients over 50 .

Pain may be a feature of both diffuse symmetrical neuropathy affecting chiefly the feet, and of some mononeuropathies, most commonly of the femoral nerve with sensory and motor symptoms in one or sometimes both thighs. In a recent report four cases of radiculopathy which caused abdominal and lower chest pain in a bandlike distribution radiating from the spine had the same features as those characterising other painful diabetic neuropathies. ${ }^{2}$ These patients were all investigated extensively, one of them by laparotomy, before the correct diagnosis was made. The results of electrophysiological investigations suggested lesions of several thoracic and lumbar nerve roots. Such cases must be unusual, though Malins ${ }^{4}$ considered that trunk pain was not rare, and Garland ${ }^{3}$ in his original description of diabetic "amyotrophy" included a case with radiculopathy initially investigated by laparotomy.

These exceptionally severe forms of neuropathy do not occur solely in established insulin-treated patients: the condition may also be found in those with relatively mild diabetes not requiring insulin and sometimes without other complications such as retinopathy or nephropathy. Occasionally neuritic symptoms are present at the onset of diabetes.

The cause of these neuropathies is complex, ${ }^{5}$ and they are certainly not specific for diabetes. Histological findings in sural nerve biopsy specimens from two patients with painful diabetic neuropathy ${ }^{6}$ indicated that the lesions were predominantly in the small fibres, and nerve sprouting has been considered as a possible cause of the pain. The presence in these patients of autonomic symptoms including impotence, sweating abnormalities, and vomiting also represents damage to small fibres. Microangiopathy was absent in these casesin contrast to mononeuropathies, where microvascular disease and infarction may be a cause; and, indeed, femoral nerve infarction has been described, ${ }^{78}$ though this may be caused by several other conditions, including polyarteritis nodosa. ${ }^{9}$

Treatment is difficult, and the symptoms tend to be distressingly protracted. Good control of diabetes should be established, by insulin if necessary. Sometimes the patient may improve rapidly after starting insulin, though inexplicably some patients also temporarily become worse. ${ }^{1}$ There is no evidence that vitamins, phenytoin, or carbamazepine have any special benefit, though they are often tried. The doctor should prescribe non-addicting analgesics and antidepressives (but judiciously), and, most importantly, give constant encouragement: the symptoms almost always resolve, though this may take several months to two years. ${ }^{1210}$

1 Ellenberg, M, Diabetes, 1974, 23, 418.

2 Longstreth, G F, and Newcomer, A D, Annals of Internal Medicine, 1977, 86, 166.

${ }^{3}$ Garland, H, British Medical fournal, 1955, 2, 1287

${ }^{4}$ Malins, J M, Clinical Diabetes Mellitus, p 214 . London, Eyre and Spottiswoode, 1968.

${ }^{5}$ Thomas, P K, and Eliasson, S G, in Peripheral Neuropathy, eds P J Dyck, P K Thomas, and E H Lambert, p 956. Philadelphia, Saunders, 1975.

${ }^{6}$ Brown, M J, Martin, J R, and Asbury, A K, Archives of Neurology, 1976, 33, 164.

Raff, M C, and Asbury, A K, New England fournal of Medicine, 1968, 279, 17.

${ }^{8}$ Raff, M C, Sangalang, V, and Asbury, A K, Archives of Neurology, 1968, 18, 487 .

${ }^{9}$ Calverley, J R, and Mulder, D W, Neurology, 1960, 10, 963.

10. Casey, E B, and Harrison, M J G, British Medical fournal, 1972, 1, 656.

\section{Difficult questions at Glasgow}

The BMA's Glasgow conference week (p 397) was not all money and militancy. Behind the regular press headlines about pay and threatened industrial action the 700 or so doctors representing consultants, general practitioners, community physicians, junior doctors, and a host of minority groups also had some sensible things to say on many other subjects ( 30 July, $p$ 327). That encouraging news has tended to be overlooked in the flurry, excitement, and forebodings over a possible confrontation with the Government about the profession's sharply falling standards of living.

Admittedly, so much medicopolitical activity in such a short space of time may have left many practising doctors, and perhaps not a few representatives, a little dazed as to what the BMA was up to in Glasgow, apart from attracting massive publicity. Briefly, the four craft conferences and the ARM were deciding on policies for the next year or beyond on subjects as varied as medical audit and London weighting for GPs, manpower, rickets in immigrant communities, pay, and nuclear safety. The intention was that, as usual, the craft conferences should debate subjects of special interest to them, such as mileage allowances for hospital doctors, and ones affecting the whole profession-manpower policy, for example. Where appropriate the decisions of these craft conferences (based on agendas that had been prepared by a joint agenda committee representing all the five meetings) were then discussed at the ARM. When crafts' views conflicted on the same subject the ARM, it was hoped, would resolve 